\title{
Depolymerization and Degradation of Humic Acids with Sodium Perborate
}

\author{
G. ALMENDROS ${ }^{1}$, F. MARTÍN ${ }^{1}$ and F.J. GONZÁLEZ-VILA ${ }^{2}$ \\ ${ }^{1}$ Instituto de Edafología y Biología Vegetal, Serrano 115 Dpdo., 28006 Madrid (Spain) \\ ${ }^{2}$ Centro de Edafología y Biologia Aplicada del Cuarto, Apdo. 1052, Sevilla (Spain)
}

(Received March 25, 1986; accepted after revision October 23, 1986)

\section{ABSTRACT}

Almendros, G., Martín, F. and González-Vila, F.J., 1987. Depolymerization and degradation of humic acids with sodium perborate. Geoderma, 39: 235-247.

Two humic acids of different origin (peat and soil) were degraded with a $5 \%$ sodium perborate solution $\left(140^{\circ} \mathrm{C}\right)$. This degradation process consists mainly of a stoichiometric production of hydrogen peroxide while the perborate is reacting with carboxyl groups of the oxidized polymers. A single perborate treatment degraded more than $40 \%$ of the humic acids to soluble products, but a 5-step oxidation was necessary for total degradation, the sample being transformed into soluble oligomers with properties similar to those of fulvic acids. The oligomeric fractions with lowest molecular weights, including individual molecules (soluble in ethyl acetate), were purified by adsorption chromatography and studied by GC-MS after methylation. The higher molecular weight fractions of oligomers were recovered over polyvinylpyrrolidone, eluted by alkali, and purified by ion-exchange chromatography ( $47 \%$ peat $\mathrm{HA} ; 25 \%$ soil $\mathrm{HA}$ ).

Degradation products included alkanes, fatty acids and dicarboxylic acids. Aromatic compounds (mainly phenolic, benzenecarboxylic and cinnamic acids), amounted to $24-50 \%$ of the total volatile degradation products. There were striking differences between peat and soil humic acids, the former yielding typical lignin degradation products. Independently checked, the perborate degradation products were not the same as those obtained by mild treatment with hydrogen peroxide under alkaline conditions.

\section{INTRODUCTION}

Considerable information on the composition and structure of humic acids (HA's) has been obtained by application of degradative techniques. Due to the complex and disordered molecular structure of humic acids and the greatly different strengths of the linkages within their molecular components, the application of a single degradative method generally identifies a partial feature of the whole polymer. If a mild degradative method (boiling water, diluted mineral acids, potassium persulphate, etc.) is used, a considerable amount of non-degraded humic acid residue remains, and the solubilized fraction gener- 
ally consists of non-humic compounds loosely joined or physically entrapped. On the other hand, drastic methods (alkaline permanganate oxidation, hydrogen peroxide, etc.) degrade the humic acid completely, producing relatively low yields of structural unities due to the predominant formation of non-structural oxidation products of low molecular weight (oxalic acid, carbon dioxide, etc.). Formation of aromatic artifacts from aliphatic structures has also been considered as a probable effect of these degradative methods (Schnitzer and Khan, 1972; Martín et al., 1984).

The low degradation yields with drastic methods are probably related to prolonged contact of degradation products with an excess of oxidizing reagent. For this reason, multi-step oxidation, or progressive addition of oxidizing reagent, has been introduced in order to minimize the destructive effects, thus increasing yields of oxidative products. The development of methods producing higher polymer fragments, and the possibility of the application of sequential degradation to the intermediate products has been proposed as an important feature of new degradative studies (Schnitzer, 1978; Martín et al., 1981).

The capacity of sodium perborate to produce hydrogen peroxide in contact with organic acids is well known. Due to the high carboxyl content of humic acids, an initial production of $\mathrm{H}_{2} \mathrm{O}_{2}$ is expected. This hydrogen peroxide would generate additional oxygen-containing functional groups in the non-degraded humic residue as a consequence of the oxidative breakdown of polymers.

Theoretically, reaction with excess sodium perborate would result in total degradation of the humic acid due to continuous production of hydrogen peroxide in equilibrium with the degree of carboxylation of the organic substrate.

In the present study, the effects of sodium perborate on humic acids were examined and the results obtained compared with the effect of a mild but direct treatment with hydrogen peroxide.

\section{MATERIAL AND METHODS}

\section{Samples}

Perborate oxidation was performed on two humic acids representative of two different humification pathways, extracted from an Umbric Cambisol under beech forest in Santander (northern, humid Spain), and from an Eutric Histosol (sapric peat) from Granada (southern Spain). Analytical characteristics of these soils and their humic acids have been reported previously (Almendros and Dorado, 1984a, b; Almendros et al., 1981).

After extraction with $0.1 \mathrm{~N} \mathrm{NaOH}$ under nitrogen, the humic acids were precipitated with $\mathrm{HCl}$ at $\mathrm{pH} 1$ and their mineral contents reduced by treatments with $\mathrm{HCl}-\mathrm{HF}(1: 1) 1 \%$ and centrifugation at $41300 \mathrm{~g}$ in alkaline $\mathrm{pH}$. HA's were finally reprecipitated, dialyzed until free of chlorides and later freezedried. 
Sodium perborate oxidation

The procedure was similar to that described for persulphate oxidation (Martín et al., 1981). $200 \mathrm{mg}$ of HA were added to a thick $100 \mathrm{ml}$ screw-stoppered glass flask and oxidized with $50 \mathrm{cc}$ of $5 \% \mathrm{NaBO}_{2} \cdot \mathrm{H}_{2} \mathrm{O}_{2} \cdot 3 \mathrm{H}_{2} \mathrm{O}$ solution $(\mathrm{pH}$ 10.7). After heating for two hours at $140^{\circ} \mathrm{C}$, the HA (completely dissolved in the perborate solution) was precipitated by drop-wise addition of concentrated $\mathrm{HCl}$. The yellow coloured digest was centrifuged and the residue was dried, weighted, and reoxidized until degradation was complete (5 treatments required).

\section{Characteristics of degradation products}

The mixture of the 5 acidified digests was extracted for more than $15 \mathrm{~h}$ using ethyl acetate. The solvent was then dehydrated with anhydrous $\mathrm{Na}_{2} \mathrm{SO}_{4}$, dried under reduced pressure and methylated with ethereal diazomethane according to the method of Schnitzer (1974). The concentrated fraction was brownish in colour, suggesting the presence of oligomeric fractions; these were removed prior to GC-MS analyses. The extract was redissolved in $\mathrm{CHCl}_{3}$ and eluted in a 5-ml glass column filled with silicagel $(0.05-0.2 \mathrm{~mm})$, using methylene chloride/hexane 4:1. The eluent was dried under $\mathrm{N}_{2}$, giving a pale yellow oil which was directly injected into a Hewlett-Packard 5992 B GC-MS computer system equipped with a $25 \mathrm{mts}$ cross-linked capillary column coated with OV-101. Oven temperature was programmed from $100^{\circ}$ to $270^{\circ} \mathrm{C}$ at a heating rate of $6^{\circ} \mathrm{C}$ $\min ^{-1}$. The flow rate of the carrier gas (He) was adjusted to $1 \mathrm{ml} \mathrm{min}^{-1}$, and the ionizing voltage was $70 \mathrm{eV}$. Identification of chromatographic peaks was achieved by comparison with data from bibliography and computer libraries and, when possible, by comparison with the MS of authentic compounds. The relative abundance of each of the identified compounds was considered as proportional to the response of an FID in a 5730A Hewlett-Packard gas chromatograph in which the samples were independently injected.

After ethyl acetate extraction of the more volatile products, the digests had a strong orange or yellow colour, indicating high proportions of water-soluble oligomers from the original HA's. This solution was chromatographed on polyvinylpyrrolidone (Polyclar AT) as described by Lowe (1975) for soil fulvic extracts. After the resin was washed by repeated dispersion in dilute alkali and acid, the digest was filtered through a Polyclar column, which retained the coloured substances. The discarded, practically colourless, eluate reacted positively to ninhydrine and anthrone. The adsorbed substances were eluted with $0.1 \mathrm{~N} \mathrm{NaOH}$, and the $\mathrm{Na}^{+}$was then eliminated by passage through a chromatographic column filled with Amberlite IR $-120 \mathrm{H}^{+}$. The eluent was freezedried, giving a friable, yellowish solid. 


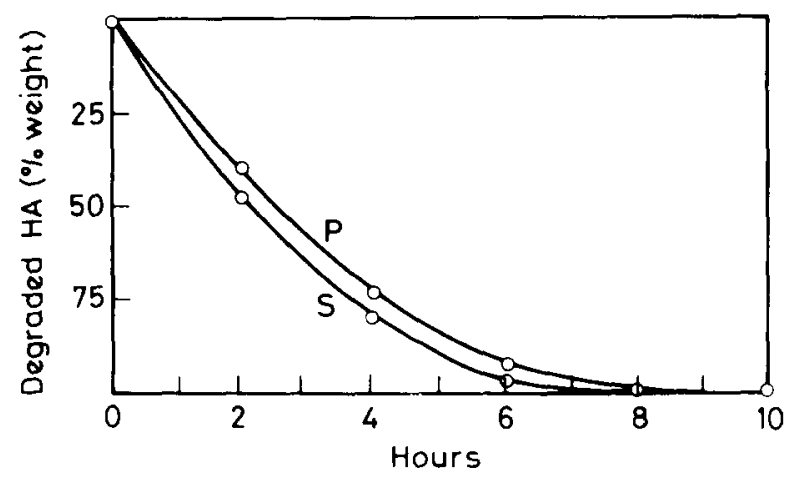

Fig. 1. Progressive degradation (measured by non-degraded ashfree weight) of soil humic acid $(\mathrm{S})$ and peat humic acid $(\mathrm{P})$ in a 5-step degradative experiment using sodium perborate.

\section{Other analyses}

Elementary compositions of the samples were determined in a HP-185 CHN microanalyzer, and their ash contents by ignition in an electric furnace, $8 \mathrm{~h}$ at $700^{\circ} \mathrm{C}$.

Visible and infrared spectra were recorded in a Shimadzu UV-240 and a Perkin-Elmer 580B, respectively, using $136 \mathrm{ppm} \mathrm{C}$ solution in $0.02 \mathrm{~N} \mathrm{NaHCO}_{3}$ in the former case (Kononova, 1961) and $\mathrm{KBr}$ pellets with $1.50 \mathrm{mg}$ of sample in the latter.

Estimation of losses of $\mathrm{C}$ during perborate oxidation were made by calculating the difference between the $\mathrm{C}$ content of $5 \mathrm{ml}$ freeze-dried aliquots of the HA's dissolved in sodium perborate before and after the 2 - $h$ reaction. Carbon was measured in a Carmhograph-12 analyzer.

Sephadex G-25 was used for gel filtration of water-soluble fractions (distilled water as eluent). Elution curves were recorded at $450 \mathrm{~nm}$ in a spectrophotometer with a continuous flow system.

Another experiment was performed in order to determine whether the perborate oxidation products were the same as those obtained by direct treatment with a proportional concentration of $\mathrm{H}_{2} \mathrm{O}_{2}$. The oxidation was not carried out at the same temperature in the closed flask because the reaction was found to be too rapid and destructive. A slow reaction at low temperature was used. HA's ( $200 \mathrm{mg}$ ) were oxidized for $48 \mathrm{~h}$ with $50 \mathrm{ml}$ of 2 vol. $\mathrm{H}_{2} \mathrm{O}_{2}$ with $400 \mathrm{mg}$ of $\mathrm{Na}_{2} \mathrm{CO}_{3}$ at room temperature.

\section{RESULTS AND DISCUSSION}

Fig. 1 and Table I show the degradation percentages and the yields of degradation products. Treatments with sodium perborate resulted in important transformations of the humic substrate: over $40 \%$ of the original weight was converted into soluble products in $2 \mathrm{~h}$. The first three of five steps were very 
Yields of degradation products obtained after sodium perborate degradations of HA's (\% ashfree weight)

\begin{tabular}{|c|c|c|c|c|}
\hline \multirow[t]{2}{*}{ Sample } & \multicolumn{2}{|c|}{$\%$ Degradation $^{\star 1}$} & \multicolumn{2}{|c|}{ Degradation products recovered $(\mathrm{mg} / \mathrm{g})$} \\
\hline & $\begin{array}{l}\text { after } 2 \mathrm{~h} \\
\text { (1st step) }\end{array}$ & $\begin{array}{l}\text { after } 10 \mathrm{~h} \\
\text { (5th step) }\end{array}$ & $\begin{array}{l}\text { alkali-soluble } \\
\text { oligomers }{ }^{\star 2}\end{array}$ & $\begin{array}{l}\text { soluble in ethyl acetate } \\
\text { (GC-MS analyses) }\end{array}$ \\
\hline Peat HA & 40.2 & 100 & 475 & 110 \\
\hline Soil HA & 53.5 & 100 & 250 & 40 \\
\hline
\end{tabular}

$\star 1 \%$ of ashfree weight.

${ }^{\star 2}$ Fraction recovered on polyvinylpyrrolidone.

effective in producing soluble substances, the last two much less effective. The phenomenon may be similar to that described for ' $\mathrm{H}_{2} \mathrm{O}_{2}$-resistant organic matter' (Griffith and Schnitzer, 1977) or may be due to linkages of humic acids with mineral components during final stages of the oxidation. After the fifth and final step, the residues (approximately $3 \%$ ) were brownish white insoluble fractions consisting of the ashes of the two samples.

No large changes in the quantitative yields from perborate oxidation were observed when reaction time or the perborate or HA concentrations were modified (half-to-double). Theoretically, complete degradation during a single oxidation is possible, but the multi-step oxidation was superior in providing concentrated digests for qualitative purposes.

Characteristics of oxidation products

The elemental compositions of water-soluble oligomers in comparison with the humic acids are shown in Table II. These degradation fractions had high oxygen contents but relatively low nitrogen contents. The atomic $\mathrm{H} / \mathrm{C}$ and

\section{TABLE II}

Elementary (ashfree) composition and spectroscopic parameters of humic acids and acid-soluble oligomers obtained after perborate oxidation

\begin{tabular}{|c|c|c|c|c|c|c|c|c|}
\hline \multirow[t]{2}{*}{ Sample } & \multirow[t]{2}{*}{$\mathrm{C}$} & \multirow[t]{2}{*}{$\mathbf{H}$} & \multirow[t]{2}{*}{0} & \multirow[t]{2}{*}{$\mathrm{N}$} & \multicolumn{2}{|c|}{ Atomic ratios } & \multirow{2}{*}{$\begin{array}{l}\text { O.D. } \\
(136 \mathrm{ppm} \mathrm{C}) \\
\text { at } 465 \mathrm{~nm}\end{array}$} & \multirow[t]{2}{*}{$\mathrm{E} 4 / \mathrm{E} 6$} \\
\hline & & & & & $\mathrm{H} / \mathrm{C}$ & $\mathrm{O} / \mathrm{C}$ & & \\
\hline Non-degraded peat $\mathrm{HA}$ & 54.33 & 3.59 & 40.26 & 1.78 & 0.79 & 0.56 & 1.39 & 4.8 \\
\hline Peat HA oligomers & 34.60 & 3.40 & 61.40 & 0.60 & 1.18 & 1.33 & 0.36 & 10.9 \\
\hline Non-degraded soil HA & 57.94 & 4.81 & 33.38 & 3.87 & 1.00 & 0.43 & 0.94 & 5.1 \\
\hline Soil HA oligomers & 37.90 & 3.25 & 57.40 & 1.45 & 1.03 & 1.14 & 0.44 & 8.4 \\
\hline
\end{tabular}




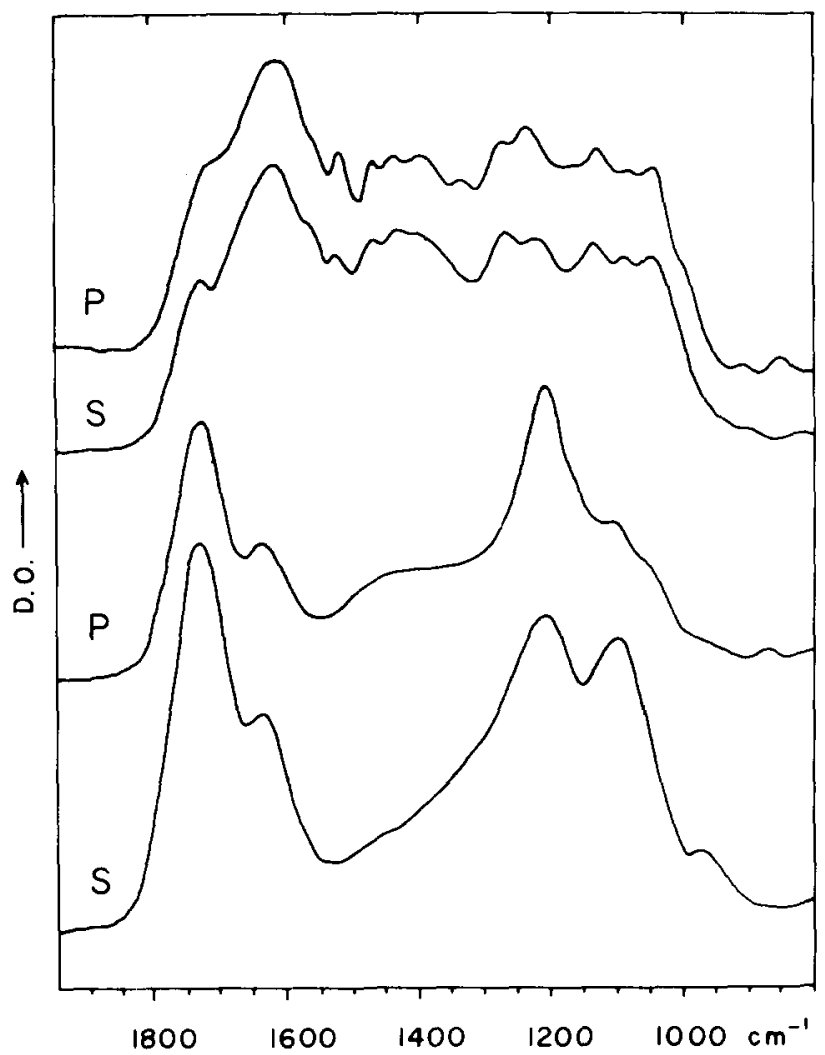

Fig. 2. Infrared spectra of the original humic acid samples (above) compared with aromatic oligomers obtained after perborate degradation of peat (P) and soil (S) humic acids (down).

O/C ratios ( Van Krevelen, 1950) are similar to those of fulvic acids. H/C ratios (frequently considered as related to the aromaticity degree) decreased slightly in comparison with soil HA's, but the $\mathrm{O} / \mathrm{C}$ ratios suggested a strong degree of carboxylation. The low specific extinctions and the high $\mathrm{E}_{4} / \mathrm{E}_{6}$ ratios were also similar to those of fulvic acids (Table II).

Infrared spectra of the oligomers showed a predominant carboxyl absorption at $1720 \mathrm{~cm}^{-1}$ (Fig. 2). The intensity of the band at $1220 \mathrm{~cm}^{-1}$ agrees with the high oxygen content. As compared to the unoxidized HA's, the intensity of the $1620 \mathrm{~cm}^{-1}$ bands (partially due to aromatic rings) decreased. Aliphatic bands at $2920 \mathrm{~cm}^{-1}$ are also present, but the $3600-2000 \mathrm{~cm}^{-1}$ region was ill defined due to the broad strong absorption of $\mathrm{O}-\mathrm{H}$ linkages near $3400 \mathrm{~cm}^{-1}$.

Gel filtration showed very reduced molecular sizes in the oligomers compared to the original humic and fulvic acids (Table III). About $80 \%$ of the compounds had molecular weights lower than 1000. Extraction of the digest with ethyl acetate had a significant effect on molecular size distribution, which 


\section{TABLE III}

Gel-filtration (Sephadex G-25) of acid-soluble fractions obtained by perborate oxidation

\begin{tabular}{|c|c|c|}
\hline Sample & Excluded fraction ( $\mathrm{Kav}=0$ ) & Retained fraction ( $\mathrm{Kav} \simeq 1$ ) \\
\hline$\overline{\text { Peat } \mathrm{HA}^{\star 1}}$ & 4.3 & 95.7 \\
\hline Peat $\mathrm{HA}^{\star 2}$ & 17.0 & 83.0 \\
\hline Soil HA ${ }^{\star 1}$ & 16.7 & 83.3 \\
\hline Soil HA ${ }^{\star 2}$ & 31.6 & 68.4 \\
\hline
\end{tabular}

${ }^{\star}$ Before ethyl acetate extraction.

${ }^{\star 2}$ After ethyl acetate extraction.

is consistent with the expected selective extraction of the fractions with the lowest molecular weights.

\section{GC-MS analyses}

In Figs. 3 and 4 and in Table IV the organic products of lowest molecular weight obtained by perborate degradation of peat and soil HA's are shown in comparison with those obtained by direct treatment with $\mathrm{H}_{2} \mathrm{O}_{2}$.
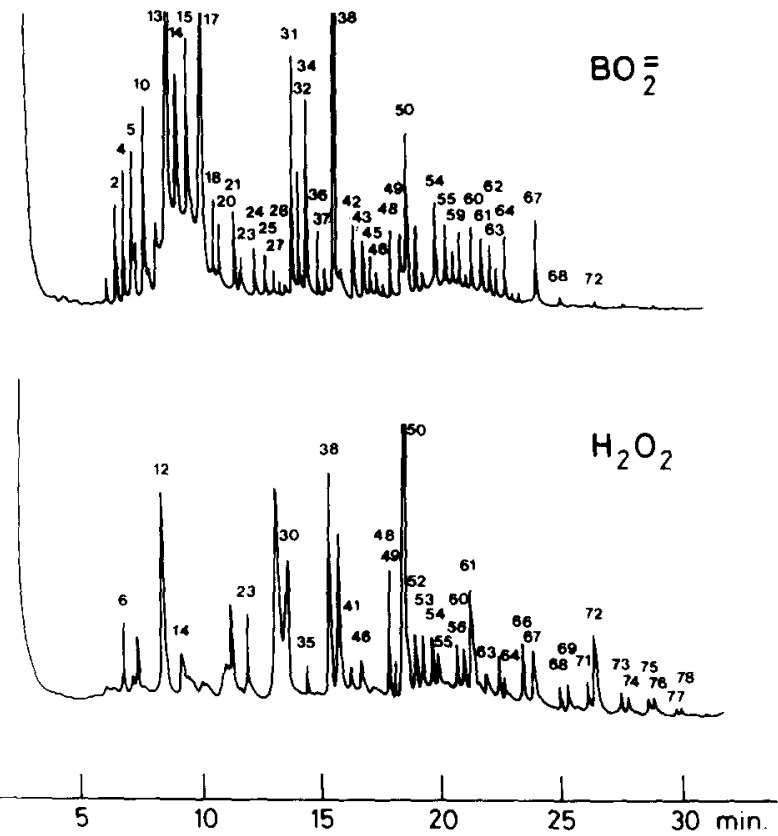

Fig. 3. Gas chromatograms corresponding to the degradation products of lowest molecular weight obtained after sodium perborate and hydrogen peroxide degradations of peat humic acid. 

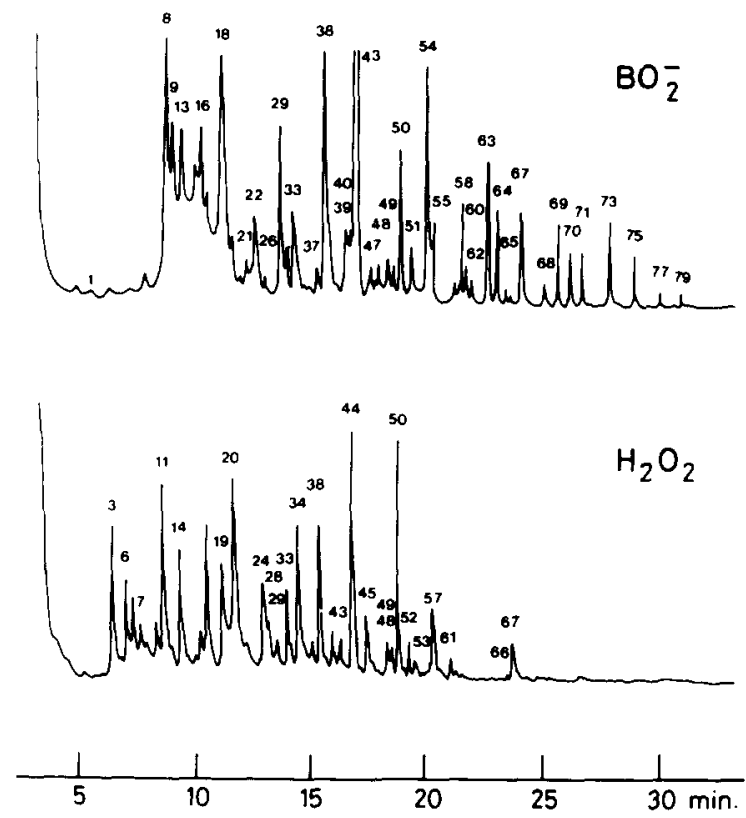

Fig. 4. Gas chromatograms corresponding to the degradation products of lowest molecular weight obtained after sodium perborate and hydrogen peroxide degradations of soil humic acid.

A considerable difference was observed in the nature of the perborate degradation products of soil and peat HA's. The highest peak in the gas chromatograph for the latter was a phenilpropenic molecule (methyl methoxy cinnamate, compound No. 17). A similar structure (methyl dimethoxy cinnamate, compound No. 25) was present only in a low proportion. The predominant peaks of peat HA oxidized with sodium perborate consisted of phenolic acids, mainly dimethoxy benzene carboxylic acids. Other degradation products were propanetricarboxylic acid, benzenetricarboxylic acids, dicarboxylic acids, and a terpenoid (dehydroabietic acid, compound No. 59). Fatty acids and alkanes were frequent, but peaks were generally small. The more abundant degradation products in the soil HA were aliphatic (palmitic acid and eicosane, compounds 38 and 43 ). The main aromatic molecules were two acetophenones ( 8 and 9 ) and phenolic acids (13 and 16). Two olefines ( 39 and 58) were also detected. Several dialkyl phthalates were also identified $(33,67)$, but these compounds, as well as dioctyl adipate (63), were probably derived from the reagents or introduced during laboratory operations.

Degradation products obtained after direct treatment with hydrogen peroxide were not the same as those produced by perborate oxidation. In the peat $\mathrm{HA}$, the predominant products were benzene di-, tri-, and tetracarboxylic acids. In the soil $\mathrm{HA}$, hydrogen peroxide yielded a higher variety of dicarboxylic ali- 
Degradation products obtained

No. Compound (methyl esters)

$\frac{\text { Peat HA }}{\text { B H }} \frac{\text { Soil HA }}{\text { B H }}$

( 1) 7-C branched dicarboxylic aliphatic acid dimethyl ester

( 2) Methoxy benzenecarboxylic acid methyl ester.

( 3) Dimethyl pimelate

(4) Propane tricarboxylic acid trimethyl ester

( 5) 9-C branched dicarboxylic aliphatic acid dimethyl ester

( 6) 1,2 Benzenecarboxylic acid dimethyl ester

( 7) Dimethyl suberate.

( 8) Dimethoxiacetophenone (I)

( 9) Dimethoxiacetophenone (II)

(10) 1,3 Benzenedicarboxylic acid dimethyl ester.

(11) 9-C branched dicarboxylic aliphatic acid dimethyl ester

(12) Paratoluensulphonic acid ethyl ester

(13) Methyl vanillate (I)

(14) Dimethoxy benzenecarboxylic acid methyl ester (I)

(15) Dimethoxy benzenecarboxylic acid methyl ester (II)

(16) Methyl vanillate (II)

(17) Methyl methoxy cinnamate

(18) C-10 branched dicarboxylic aliphatic acid dimethyl ester

(19) Methoxy benzenedicarboxylic acid dimethyl ester

(20) Trimethoxy benzenecarboxylic acid methyl ester

(21) n-heptadecane

(22) Dimethyl decanedioate.

(23) Methyl tetradecanoate

(24) Methoxy benzenedicarboxylic acid dimethyl ester (I)

(25) Methyl dimethoxy cinnamate.

(26) Methoxy benzenedicarboxylic acid dimethyl ester

(27) 15-C branched fatty acid methyl ester (I)

(28) 1,2,3, Benzene tricarboxylic acid trimethyl ester.

(29) n-octadecane

(30) 1,2,4, Benzene tricarboxylic acid trimethyl ester.

(31) 15-C branched fatty acid methyl ester (II)

(32) Methyl pentadecanoate

(33) $\mathrm{Di}$ isobutyl phthalate

(34) Benzene tricarboxylic acid trimethyl ester

(35) Dimethyl decanedioate

(36) Methyl hexadecanoate

(37) n-nonadecane

(38) Methyl hexadecanoate.

(39) Olefine $>10-\mathrm{C}$

(40) 17-C branched fatty acid methyl ester (I)

(41) Branched alkane

(42) 17-C branched fatty acid methyl ester (II)

(43) n-eicosane

(44) Methoxy benzenetricarboxylic acid trimethyl ester (I)

$\begin{array}{llll}- & - & + & - \\ + & - & - & - \\ - & - & - & \star \\ + & - & - & - \\ + & - & - & - \\ - & \star & - & + \\ - & - & - & + \\ - & - & \star & - \\ - & - & \star & - \\ \star & - & - & - \\ - & - & - & \star \\ - & \star & - & - \\ \star & - & \star & - \\ \star & + & - & \star \\ \star & - & - & - \\ - & - & \star & - \\ \star & - & - & - \\ \star & - & \star & - \\ - & - & - & \star \\ + & - & - & \star \\ + & - & + & - \\ - & - & \star & - \\ + & + & - & - \\ + & - & - & \star \\ + & - & - & - \\ - & - & + & - \\ + & - & - & - \\ + & - & - & + \\ - & - & \star & + \\ - & \star & + & - \\ \star & - & - & - \\ \star & - & - & - \\ - & - & + & + \\ \star & - & - & \star \\ - & + & - & - \\ + & - & - & - \\ \star & - & + & + \\ \star & \star & \star & \star \\ - & - & + & - \\ - & - & + & - \\ - & + & - & - \\ + & - & - & - \\ + & - & \star & + \\ - & - & - & \star \\ & & & \end{array}$


No. Compound (methyl esters)

(45) Methoxy benzenetricarboxylic acid trimethyl ester (II)

(46) Methyl heptadecanoate

(47) Methyl octadecadienoate

(48) Methyl octadecenoate.

(49) n-heneicosane.

(50) Methyl octadecanoate

(51) Branched alkane

(52) 1,2,3,5 Benzene tetracarboxylic acid tetramethyl ester.

(53) C-19 branched fatty acid methyl ester.

(54) n-docosane

(55) Methyl nonadecanoate

(56) C-20 unsaturated fatty acid methyl ester

(57) Dimethyl hexadecanedioate

(58) Olefine $>15-\mathrm{C}$

(59) Methyl dehydroabietate

(60) n-tricosane....

(61) Methyl eicosanoate.

(62) Branched alkane

(63) Dioctyl adipate

(64) n-tetracosane.

(65) 22-C unsaturated fatty acid methyl ester

(66) 22-C branched fatty acid methyl ester.

(67) Dicyclohexyl phthalate

(68) n-hexacosane

(69) Methyl tricosanoate.

(70) Branched alkane

(71) n-heptacosane

(72) Methyl tetracosanoate

(73) n-octacosane

(74) Methyl pentacosanoate

(75) n-nonacosane.

(76) Methyl hexacosanoate.

(77) n-triacontane

(78) Methyl heptacosanoate

(79) n-hentriacontane

Legend. Roman numbers indicate different isomers. Compound abundance: $+=$ present $(0.1-3 \%$ of total volatile products) ; $\star=$ abundant ( $>3 \%$ of total volatile products). Methods: $\mathrm{B}=$ sodium perborate; $\mathrm{H}=$ hydrogen peroxide. 
Total abundance ${ }^{\star 1}$ and relations between different groups of degradation products

\begin{tabular}{|c|c|c|c|c|}
\hline & \multicolumn{4}{|c|}{ Oxidizing reagents } \\
\hline & \multicolumn{2}{|c|}{ peat HA } & \multicolumn{2}{|c|}{ soil HA } \\
\hline & $\mathrm{B}^{\star 2}$ & $\mathrm{H}$ & $\mathrm{B}$ & $\mathrm{H}$ \\
\hline Dicarboxylic aliphatic acids & 6.19 & 0.71 & 3.48 & 10.75 \\
\hline Total alkanes & 7.61 & 8.78 & 35.26 & 5.51 \\
\hline Branched alkanes & 1.18 & 0.00 & 2.90 & 0.00 \\
\hline Alkane range & $17-26$ & $21-30$ & $17-31$ & $18-21$ \\
\hline Fatty acids & 10.16 & 54.89 & 18.64 & 16.65 \\
\hline Fatty acids range & $14-24$ & $14-27$ & $16-23$ & $16-22$ \\
\hline Phenolic acids & 22.40 & 0.72 & 10.36 & 27.51 \\
\hline Benzenecarboxylic acids & 10.39 & 7.30 & 1.39 & 9.25 \\
\hline Total aromatics & 50.00 & 16.25 & 23.60 & 41.72 \\
\hline Unidentified & 11.60 & 9.52 & 3.11 & 12.80 \\
\hline Aliphatics/aromatics & 0.48 & 3.96 & 2.43 & 0.79 \\
\hline Benzenecarboxylic/phenolics & 0.46 & 10.14 & 0.13 & 0.34 \\
\hline Aliphatics/phenolics & 1.06 & 89.41 & 5.53 & 1.19 \\
\hline Aliphatics/benzenecarboxylics & 2.30 & 8.81 & 41.28 & 3.55 \\
\hline
\end{tabular}

* Percentage of the total volatile compounds, calculated from peak areas obtained with a flame ionization chromatographic detector.

-2Methods: $\mathrm{B}=$ sodium perborate; $\mathrm{H}=$ hydrogen peroxide.

phatic acids, the predominant peaks corresponding to a methoxy benzenetricarboxylic acid and to stearic and trimethoxy benzenecarboxylic acids.

The different results with the two degradation techniques are shown by cumulative data in Table V. Higher percentages of aromatic compounds (mainly cinnamic and phenolics ), were obtained by perborate oxidation of the peat HA than of the soil HA. In contrast, a higher percentage of aromatics was obtained by hydrogen peroxide oxidation from the soil than the peat HA. Hydrogen peroxide also produced a higher benzenecarboxylic/phenolic ratio than did perborate oxidation.

Differences between the series of alkanes and fatty acids produced by sodium perborate and direct hydrogen peroxide treatments were small. Palmitic and stearic acids were predominant in both the peat and soil HA's. In samples treated with hydrogen peroxide, however, the 18-C fatty acid (compound No. 
50) predominated over the 16-C homologue, and the proportions of the other fatty acids were relatively low (Figs. 3 and 4 ).

\section{CONCLUSIONS}

Our results suggest that perborate oxidation of humic acids produces moderate breakdowns of the macromolecules, yielding a series of oligomeric fractions. The fractions with lowest molecular weights are soluble in ethyl acetate and contain a proportion of individual monomers which can be directly studied by GC-MS.

The proposed technique may be considered a mild degradation method, as shown by the high yield of oligomeric products and the relatively low loss of $\mathrm{C}$ by oxidation to $\mathrm{CO}_{2}$ (estimated at $10 \%$ of the total $\mathrm{HA}$ carbon after each step). Nevertheless, the degradation products from perborate oxidation differ appreciably from those obtained by other mild techniques such as water or acid hydrolysis (Haworth, 1971) or persulphate oxidation (Martín et al., 1981). These mild degradations produce non-degradable residues (ABHA, PBHA) that cannot be significantly oxidized by repeating treatments. The existence of these 'resistant humic moieties' has often been considered as a consequence of a 'binary' composition of complex molecules having a condensed 'core'. The formation of these resistant residues might also be explained by condensation reactions occurring during oxidation. According to Wershaw et al. (1977), humic macromolecules are considered as a hierarchic association of structural units joined by a continuous series of linkages with different stabilities (covalent, H-bonds, steric impedimental). The results from perborate oxidation agree with this second model, as suggested by the continuous degradation that completely solubilizes the sample. Comparison of the oxidation products independently extracted after a 3-step perborate degradation showed the same major chromatographic peaks after each of the degradation phases.

There are striking differences between the nature of the partially degraded products obtained with perborate and those obtained with the mild techniques which produce a 'condensed residue'. The latter are high molecular weight substances of a humic acid type generally showing a higher aromaticity and specific extinction, a lower carboxyl content and a consequently reduced solubility as compared to the original HA's. In contrast, the partially degraded products obtained by treatment with perborate are fulvic acid-like oligomers showing a low degree of condensation and high contents of oxygen-containing groups. These oligomer fractions may be subjected to further degradation, using the same or different degradation techniques, to yield new fractions of individual molecules.

Direct oxidation with hydrogen peroxide was considered a non-reproducible degradation technique, which probably distorts quantitative data due to 
uncontrolled oxidative processes (high benzene carboxylic/phenolic ratios, and a probable preferential oxidation of the lower MW fatty acids, etc.).

The mechanisms of the perborate degradation may consist of a series of complementary reactions involving peroxidation together with an alkaline solvolysis similar to that described for lignin polymers (Wallis, 1971). Perborate seems to be an adequate reagent for degradation of humic molecules with a low degree of diagenesis or transformation, such as peat and compost humic fractions.

\section{REFERENCES}

Almendros, G., Dorado, E. and Polo, A., 1981. Contribución al estudio analítico de la turbera de Padul (Granada). An. Edafol. Agrobiol., 40: 163-178.

Almendros, G. and Dorado, E., 1984a. Estudio de acidos húmicos de tipo P. Fraccionamiento en columna de sepiolita. Valoración cuantitativa de pigmentos. An. Edafol. Agrobiol., 43(1-2): $153-165$.

Almendros, G. and Dorado, E., 1984b. Estudio de acidos húmicos de tipo P. Distribución de los pigmentos verdes en las diferentes fracciones húmicas del suelo. An. Edafol. Agrobiol., 43: 547-559.

Griffith, S.M. and Schnitzer, M., 1977. Organic compounds formed by the hydrogen peroxide oxidation of soils. Can. J. Soil Sci., 57: 223-231.

Haworth, R.D., 1971. The chemical nature of humic acid. Soil Sci., 111: 71-79.

Kononova, M.M., 1961. Soil Organic Matter. Pergamon, London, 450 pp.

Lowe, L.E., 1975. Fractionation of acid-soluble components of soil organic matter using polyvinyl pyrrolidone. Can. J. Soil Sci., 55: 119-126.

Martín, F., Saiz-Jiménez, C. and González-Vila, F.J., 1981. The persulfate oxidation of a soil humic acid. Soil Sci., 132: 200-203.

Martín, F., González-Vila, F.J. and Lüdemann, H.D., 1984. About the similarity between polymaleic acid and water soluble humic substances. Z. Naturforsch., 396: 244-248.

Matsuda, K. and Schnitzer, M., 1972. The permanganate oxidation of humic acids extracted from acid soils. Soil Sci., 114: 185-193.

Schnitzer, M. and Khan, S.U., 1972. Humic Substances in the Environment. Marcel Dekker, New York, N.Y., $327 \mathrm{pp}$.

Schnitzer, M., 1974. The methylation of humic substances. Soil Sci., 117: 94-102.

Schnitzer, M., 1978. On permanganate oxidation of HA - A discussion. Geoderma, 21: 239-243.

Van Krevelen, D.W., 1950. Graphical-statistical method for the study of structure and reaction processes of coal. Fuel, 29: 264-284.

Wallis, A.F.A., 1971. Solvolysis by acid and bases. In: K.V. Sarkanen and C.H. Ludwig (Editors), Lignins. Wiley Interscience, New York, N.Y., pp. 361-369.

Wershaw, R.L., Pinckney, D.J. and Boocker, J.E., 1977. Chemical structure of humic acids, 1. A generalized structural model. Res. U.S. Geol. Surv., 5: 565-569. 